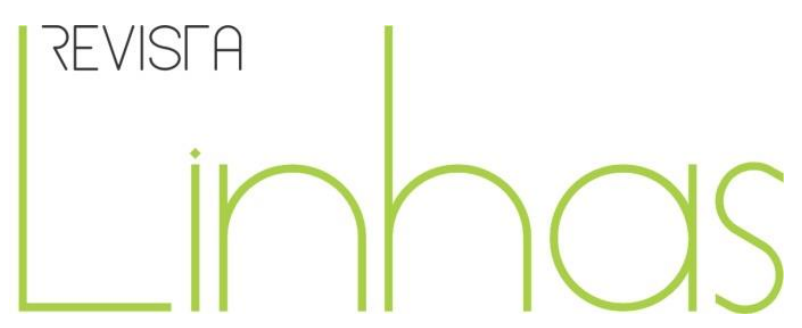

\title{
Ecossistema educomunicativo: comunicação e aprendizagem em rede
}

\begin{abstract}
Resumo
Ensino remoto, aula assíncrona e plataforma de comunicação são termos, entre outros, que entram no vocabulário do cotidiano das pessoas desde que a pandemia de Covid-19 nos forçou ao isolamento social em março de 2020. Esse fato tornou relevante a discussão sobre os ecossistemas de comunicação possibilitados pela importância das mídias em nosso cotidiano, seja no trabalho, nas relações familiares e nas escolas. Com a pandemia de Covid-19, as mídias adquiriam um papel ainda mais relevante no nosso cotidiano e sua inserção na prática escolar deixa de ser a discussão da ordem do dia para ser o processo comunicacional que cada uma viabiliza. Neste artigo, identificamos como a comunicação é feita nos Modos Estrela, Círculo e Rede e qual ecossistema de comunicação corresponde a cada um e discutimos como o conceito de ecossistema torna-se interessante para compreender os processos comunicacionais e educacionais. Propomos, por fim, o esquema de um ecossistema educomunicativo como uma ferramenta para, a partir do aprendido durante a pandemia, elaborar propostas para a pós-pandemia.
\end{abstract}

Palavras-chave: Ecossistema comunicativo. Ecossistema de aprendizagem. Ecossistema educomunicativo. Aprendizagem em rede.

\author{
Ademilde Silveira Sartori \\ Universidade do Estado de Santa \\ Catarina - UDESC - Florianópolis/SC \\ - Brasil \\ ademildesartori@gmail.com
}

\footnotetext{
Para citar este artigo:

SARTORI, Ademilde Silveira. Ecossistema educomunicativo: comunicação e aprendizagem em rede. Revista Linhas. Florianópolis, v. 22, n. 48, p. 62-79, jan./abr. 2021.
}

DOI: $10.5965 / 1984723822482021062$

http://dx.doi.org/10.5965/1984723822482021062 


\title{
Educommunicative ecosystem: communication and networked learning
}

\begin{abstract}
Remote education, asynchronous class and communication platform are terms, among others, that have entered the vocabulary of people's daily lives since the Covid-19 pandemic forced us to social isolation in March 2020. This fact made the discussion very relevant communication ecosystems whether at work, family relationships and schools. With the Covid19 pandemic, the media acquired an even more relevant role in our daily lives and their insertion in school practice is no longer the discussion of the order of the day, but the communication process they make possible. In this article, we identify how communication is done in Star, Circle and Network Modes and which communication ecosystem corresponds to each one and discuss how the concept of ecosystem becomes interesting to understand the communicational and educational processes. Finally, we propose a schematic of an educommunicative ecosystem as a tool to, based on what was learned during the pandemic, elaborate proposals for the postpandemic.

Keywords: Communicative ecosystem. Learning ecosystem. Educommunicative ecosystem. Network learning.
\end{abstract}


Ensino remoto, educação a distância, ensino híbrido, aula assíncrona e plataforma de comunicação são termos, entre outros, que entraram no vocabulário cotidiano de milhares de pessoas desde que a pandemia de Covid-19 nos forçou ao isolamento social, em março de 2020. Profissionais das mais variadas áreas passaram a realizar seu trabalho em casa por meio da internet, intensificando a prática do teletrabalho. Nesse processo, rotinas e práticas foram reinventadas. Profissionais do teatro, por exemplo, reinventaram processos artísticos e criaram modelos de negócios para que pudessem se apresentar para plateias virtuais. Houve quem tentasse evitar, mas, mais cedo ou mais tarde, participou de uma "live" para discutir algum tema relativo ao seu ofício e, certamente, assistiu a muitas delas uma vez que esse se tornou o formato mais comum de debate, de apresentação e de interação. Dispositivos móveis, como o tablet e o smartphone, passaram a desempenhar papel importante na rotina hospitalar durante a pandemia na busca por colocar doentes e familiares em contato. Famílias passaram a usar intensamente aplicativos de comunicação para a circulação de seus afetos e atualização das informações.

A partir das orientações da UNESCO (2020) para o enfrentamento da pandemia de Covid-19, as escolas assumiram o ensino remoto. Da educação infantil ao ensino superior, tiveram suas atividades de ensino suspensas a partir da segunda semana de março, sem previsão de retorno, e o Ministério de Educação determinou a não obrigatoriedade dos 200 dias letivos, desde que fossem cumpridas 800 horas anuais. Estudantes passaram a receber educação escolar em seus lares. Atividades pedagógicas, orientações instrucionais, materiais didáticos agora convivem com a realização do trabalho por parte de muitos pais, com o convívio compulsório entre irmãos e parentes, com animais de estimação, enfim, todos disputando espaços para estudo, trabalho e lazer, enfrentando problemas tecnológicos para comunicação e dificuldades de acesso.

O país passou a confrontar suas diferenças geográficas, de infraestrutura e a crueldade de uma divisão de renda que exclui dos benefícios tecnológicos a maioria da sua população. As dimensões continentais são um desafio maior para comunidades distantes dos centros urbanos, notadamente aquelas que se encontram em distâncias medidas em hora de barco rio acima ou rio abaixo e sem infraestrutura tecnológica que 
pudesse viabilizar a manutenção da relação pedagógica entre estudantes e professores. Testemunhamos as mais variadas experiências e as mais variadas soluções.

De uma maneira ou de outra, as pessoas se envolveram com mídias no seu trabalho, no convívio familiar e na formação escolar. Na escola, a alteração se deu de modo a causar desequilíbrios e tensões no ecossistema comunicativo escolar tradicional no qual a mídia tinha papel apenas de ferramenta didática. $O$ isolamento social que submeteu professores, gestores, familiares e estudantes a uma rotina pedagógica inédita, serviu de força motora para uma relação intensa com as mídias e com o desenvolvimento de práticas pedagógicas educomunicativas a partir do movimento de busca por manter as atividades escolares funcionando, ainda que a sala de aula tenha se deslocado para a sala de jantar e, muitas vezes, para o quarto de dormir.

Nesse contexto, convém refletir sobre quais características da comunicação possibilitam o desenvolvimento de um ecossistema educomunicativo, colocando em foco a aprendizagem em rede, a criação coletiva dos sentidos, o que joga luz na relação mídia e escola.

\section{Em busca de conexões}

Desde Umberto Eco (2004), costumamos chamar de integrados e apocalípticos aos que se relacionam com as mídias de modo otimista ou crítico, respectivamente. Devemos à tradição prometeica as visões emancipatórias das tecnologias (MARTINS, 1997) e à fáustica, as perspectivas de manipulação e domínio utilitarista da natureza e a tecnologia como uma armadilha (RÜDIGER, 2013).

Quando consideramos a relação da escola com a mídia, podemos simplificar em três perspectivas diferentes que nos remetem tanto a tempos históricos quanto a abordagens teóricas específicas. A primeira, é uma relação de suspeita da escola em relação à mídia, na medida em que a enxergava como meio de propagação de valores e atitudes que deveriam estar sob vigilância. Devemos, em grande medida, essa suspeita aos estudos críticos das mídias como indústrias culturais pela Escola de Frankfurt que as viam como agências reprodutoras da dominação capitalista por meio de suas estratégias persuasivas, de manipulação e homogeneização dos gostos, pela mercantilização da 
cultura. A leitura das mídias deveria ser crítica, crianças e jovens deveriam ser alfabetizados midiaticamente para serem capazes de entender e evitar processos que poderiam sujeitá-los às suas performances comerciais e ideológicas.

Essa visão teórica dicotômica levou o esforço pedagógico dos programas de Educação para os Meios a se concentrarem na desmistificação do sentido ideológico das mensagens pelos receptores, tentando vaciná-los contra os conteúdos veiculados. Os meios de comunicação foram assumidos quase sempre como maléficos que deviam ser combatidos. (VASSALO DE LOPES, 2011, p. 44)

A outra perspectiva, poderíamos chamar de progressivista, tinha como principal demanda a inserção de tecnologias digitais, computador e internet, para enriquecer o processo pedagógico e oferecer acesso à informação. A inserção das tecnologias digitais da informação e da comunicação teria papel de atualizar a escola para o momento altamente mediado e conectado no qual a sociedade se encontra e aponta para a intensificação que se projeta para o futuro.

O computador é também um instrumento de precisão para a pesquisa pedagógica. Por seu intermédio, todos os alunos podem ser submetidos exatamente ao mesmo programa de ensino e podem-se registrar em detalhe suas progressões, seus atrasos e erros. Os autores de softwares didáticos aperfeiçoam seus produtos ao progredir no conhecimento dos mecanismos do aprendizado. Quando se trata, para o aluno, de apropriar-se um conjunto predefinido de conhecimentos fatuais, ou dominar um código simples (como as leis do trânsito), a máquina pode pura e simplesmente substituir o professor humano. Nos outros casos, a máquina relaxa a relação dual entre professor e aluno. A transmissão de informações e a notação dos exercícios deixam de ser a principal função do professor. Guiando a procura do aluno por informações nos programas, nos bancos de dados e nos livros, ajudando-o a formular seus problemas, torna-se um animador de aprendizado. (LÉVY, 1998, p. 27)

A terceira perspectiva, a da educomunicação, busca uma relação de diálogo crítico entre escola e mídia uma vez que as entende como instâncias de formação cultural, sendo ambas tecnologias comunicacionais. A educomunicação é um campo do conhecimento que surgiu na década de 1990, fruto dos estudos do Núcleo de Comunicação e Educação da USP (NCE-USP) e busca entender todas as relações entre a educação e a comunicação nas suas mais diversas dimensões e, entre elas, as relações 
existentes entre a escola e as mídias, tanto críticas quanto de produção, expressão e gestão de processos comunicativos (SOARES, 2011). Parte do entendimento de comunicação definido por Paulo Freire como construção coletiva do conhecimento, “[...] um encontro de sujeitos interlocutores que buscam a significação dos significados" (FREIRE, 1979, p. 69). Assim, compreende-se a importância dada à comunicação expressa por Martín-Barbero (2011, p. 123) quando destaca “[...] que nada pode prejudicar mais a educação do que nela introduzir modernizações tecnológicas sem antes mudar o modelo de comunicação que está por debaixo do sistema escolar."

Para pensarmos os modelos de comunicação subjacentes ao sistema escolar, pode ser interessante refletirmos sobre a diversidade de termos que se referem aos artefatos e processos tecnológicos que participam da prática pedagógica. Antes da chegada do computador na escola, era comum o termo "recurso audiovisual” para o cinema, a rádio e a televisão. Usamos, também, o termo "recursos de ensino" para todo e qualquer artefato ou equipamento tecnológico, quer seja o mimeógrafo, a cartolina ou o livro didático. Passamos a interagir com as "TICs", as antigas tecnologias, e adotamos a sigla "NTICs" para denominar as novas tecnologias da informação e da comunicação. Logo percebemos que, com a digitalização, tanto a televisão, a rádio, o jornal e mesmo o livro perderam a característica de "analógicos" e passaram a incorporar as tecnologias digitais que, ao adentrarmos os anos 2000, passamos a denominar "mídias". Enfim, passamos a perceber que o processo comunicacional é a dimensão que melhor caracteriza a relação com as mídias e tecnologias, a comunicação e sua relação com a educação entram em cena'.

Essa mudança de termos não é uma mera preferência terminológica, é um “deslocamento de referências" (SARTORI, 2015, p. 114) que nos revela como a escola se relaciona com a cultura por meio das tecnologias e que a preocupação se desloca de uma visão instrumental para a compreensão de ecossistemas comunicativos. O que se constata é que a mudança não é de tecnologias analógicas para digitais, tampouco uma questão de velhas ou novas, mas de tecnologias de portabilidade e transmissão da

\footnotetext{
1 Um marco nesse processo pode ser identificado na mudança do nome da associação americana de audiovisual, a maior do mundo, de "Department of Audiovisual Instruction" para "Association for Educational Communication and Technology", em 1970 (PARRA, 1977). Embora a perspectiva tenha sido voltada a conceber a tecnologia educacional como análise de sistema, o termo comunicação educacional desloca para o processo de comunicação o que antes era visto como recurso didático.
} 
informação para tecnologias que proporcionam conectividade, ubiquidade, coletividade e aprendizagem em rede. Trata-se da mudança do paradigma epistemológico da aprendizagem. Aqui a escola encontra duas dificuldades: a primeira é compreender como as dinâmicas comunicacionais se modificaram e quais suas implicações para a sociedade, a segunda é compreender essas dinâmicas dentro do contexto das concepções educacionais. A primeira implica superar a visão instrumental das mídias para uma compreensão cultural da sociedade mediada e midiatizada; a segunda diz respeito à relação entre os ecossistemas comunicacionais e os ecossistemas de aprendizagem.

\section{Do viés instrumental para os modos de comunicação}

Colocar os modos de comunicação em primeiro plano é compreender a relação com a mídia não pelo tradicional olhar do desenvolvimento histórico, na linha de tempo que segue a sequência impresso-cinema-rádio-televisão-internet. A linha de tempo pode não ter o objetivo, mas facilmente nos leva a imaginar que juntamente com o desenvolvimento vem progresso e melhoria, como se as tecnologias mais antigas tivessem um potencial menor de atender às demandas educacionais ou tivessem um impacto menor na cultura. O olhar proposto aqui é os dos modos de comunicação, ou modos de interação (SARTORI, 2009; SARTORI, 2017) viabilizados por elas.

\section{Modo Estrela:}

No Modo Estrela, a comunicação ocorre de um-para-um, a fonte emissora emite a mensagem e o receptor a recebe isolada e individualmente. É o modo de comunicação típico de projetos educacionais desenhados para distribuir conteúdo para estudantes dispersos. A concepção de aprendizagem geralmente é instrucional, individualizada, com recebimento de pacotes de conteúdos prontos, caracterizando a concepção educativa que Paulo Freire chamou de bancária. A comunicação é assíncrona cujas possibilidades de interação entre estudantes ou mesmo entre estudantes e professores aumentou com a chegada da internet. Foi um modelo muito utilizado na educação a distância (EaD) préinternet, que utilizava material didático impresso, geralmente chamado de ensino por 
correspondência, mas que continua sendo utilizado em cursos de curta duração com viés instrucionista (NEVES, 2004, p. 57) oferecidos pela internet, com a grande vantagem da possibilidade imediata de retorno dos resultados da avaliação da aprendizagem. 0 ecossistema comunicativo desse modo de interação inicialmente pouco interativo, vem sendo abandonado na medida em que a interatividade viabilizada pela internet cresce e as pessoas vão se inserindo na cultura da participação e da conectividade.

\section{Modo Círculo:}

No Modo Círculo, a comunicação ocorre de um-para-muitos, com receptores dispersos e emissão centralizada, a mensagem é não personalizada e massificada. Típica das tecnologias broadcasting como rádio e televisão aberta e terrestre. O desenho pedagógico é centralizado na fonte que transmite aulas, pré-gravadas ou não, baseado na entrega de conteúdos conforme concepção bancária. As possibilidades de interação dos alunos entre si são restritas e entre os estudantes e os professores seria quase inexistente não fossem as alternativas de salas de recepção utilizadas em diversos programas de EaD que viabilizam um certo grau de interação entre os estudantes e com os tutores. A interação com professores é viabilizada pela internet, quando o acesso é possível. No Brasil, a televisão digital chegou a prometer interatividade a ponto de viabilizar uma EaD mais dialógica, mas essa promessa ficou no papel por não ter "[...] interatividade plena e com uma reduzida gama de serviços" (LIMA JÚNIOR, 2009, p. 379). Nesse modo de interação, a comunicação é síncrona e não permite flexibilidade de horário uma vez que a audiência tem horário determinado. O ecossistema comunicativo é massivo, unidirecional e não dialógico. Assim como o Modo Estrela, vem se modificando em função das possibilidades oferecidas pela internet e pelos aplicativos de comunicação, com os quais as pessoas vão se inserindo na cultura da participação e da conectividade.

\section{Modo Rede:}

No Modo Rede, a comunicação se dá pelas mais variadas formas: um-para-um, umpara-muitos e muitos-para-muitos. Tanto é possível publicar conteúdo para um grande 
público, como em um site na internet, quanto comunicar-se em pequenos grupos por meio de aplicativos de smarthpnones, ou individualmente pelo correio eletrônico. Nesse ecossistema comunicativo, fonte e recepção são híbridos, são 'emirecs', emissores e receptores, ou 'prosumer', produtores e consumidores ao mesmo tempo, e todas as formas de comunicação são utilizadas para os mais diversos propósitos. As características básicas são o complexo de possibilidades comunicativas, a interação intensa, a produção coletiva, a coautoria, a portabilidade, a mobilidade, a conectividade, a ubiquidade e a aprendizagem em rede.

A ideia de rede traz a conexão de muitos nós, com centros ou multicentros conectados entre si ou não, de modo não necessariamente permanente, não necessariamente estático no tempo-espaço. Para compreendermos o ecossistema comunicativo que funciona em rede é necessário discutir a cultura da convergência na qual conteúdos fluem por múltiplas plataformas de mídias, a cultura participativa na qual o processo de consumo tornou-se coletivo (JENKINS, 2009) e a cultura da inteligência que, para Lévy, é “[...] distribuída por toda parte” (p. 29, 1998). Pensando sobre o conhecimento na era das redes, Lévy chama a atenção à cognição e chama de ecologias cognitivas as estruturas que "[...] resultam das dinâmicas ecológicas concretas” (LÉVY, 1993, p. 149). Como ecologia é o estudo da relação entre os seres vivos e seus ambientes, ou seja, o estudo dos ecossistemas, entendemos o Modo Rede como um complexo de ecossistemas comunicativos.

\section{Ecossistemas comunicativos}

Ernst Heinrich Haeckel (1834 - 1919) criou o neologismo “ecologia” que une duas palavras gregas: “oikos" (casa) e "logos" (estudo), para se referir à ciência das relações do organismo com o ambiente (EGERTON, 2013). Arthur George Tansley (1871-1955) cria o neologismo "ecossistema" para se referir às relações entre seres vivos e fatores ambientais (CAMERON, 2017). Os seres vivos devem ser compreendidos dentro do seu ambiente, com todas as relações de interdependências entre si e os diversos fatores do ambiente onde vivem. A todo conjunto de relações bióticas e abióticas relacionadas a uma população, chama-se ecossistema. 
Os termos 'ecologia' e 'ecossistema' não ficaram restritos à Biologia. Em 1977, Michael T. Hannan e John Freeman propõem as bases da Ecologia Organizacional que busca compreender questões como o crescimento das organizações e suas relações de competitividade, sucesso e falência considerando a organização como ser vivo (HANNAH; FREEMAN, 1977). Na mesma época, surge a ideia de uma 'ecologia industrial' a partir do artigo intitulado 'Estratégias para a manufatura', de Robert Frosch e Nicholas Gallopoulos, publicado em 1989 pela Scientific American, no qual sugeriram a necessidade de um ecossistema industrial que otimizasse recursos e minimizasse a poluição ambiental (ISIE, 2009). Assim, a partir da Ecologia que se preocupa com as relações de interdependência entre seres vivos e seus ambientes, passamos a pensar em ecossistemas de negócios, ecossistemas digitais, ecossistemas de formação, ecossistemas de inovação, ecossistemas comunicativos, ecossistemas digitais, ecossistemas de aprendizagem etc.

Na América Latina, Jesús Martín-Barbeiro foi o estudioso das comunicações que nominou de ecossistema comunicativo o ambiente comunicacional no qual estamos inseridos, chamando a atenção para a necessidade de se discutir o ecossistema comunicativo da mesma maneira como discutimos o ecossistema verde. Ao assinalar que a escola acaba por escamotear o ecossistema comunicativo, identifica a defasagem entre o modelo de comunicação da escola e os modelos de comunicação que moldam a sociedade atual. "El problema es que, más allá de las tecnologías, a lo que estamos asistiendo, es a la emergencia de un ecosistema visual y sonoro, que adquiere aceleradamente tanta vigencia como el ecosistema natural" (MARTíN-BARBERO, 1999, p. 15). O ecossistema comunicativo se revela na relação com as tecnologias, mas também nas novas sensibilidades que trazem. Martín-Barbeiro defende a necessidade de superar a visão instrumental das mídias nas práticas pedagógicas para que a educação possa ser inserida “[...] nos complexos processos de comunicação da sociedade atual - o ecossistema comunicativo que constitui o ambiente circundante." (MARTÍN-BARBEIRO, 2003, p. 68, grifo do autor).

Os ecossistemas comunicativos adquirem tanta importância em nossa sociedade conectada que obtiveram status de objetos de pesquisa do Programa de Pós-Graduação em Ciências da Comunicação da Universidade Federal do Amazonas (PPGCCOM/UFAM), 
com uma linha de concentração intitulada “Ecossistemas Comunicacionais", entendendo que:

Trata-se de um campo de estudos que focaliza a diversidade e ao mesmo tempo a unidade de fenômenos interconectados e interdependentes que envolvem as práticas comunicativas, instituindo processos em rede que tensionam as fronteiras disciplinares da investigação científica frente à complexidade do objeto, exigindo pesquisas interdisciplinares e transdisciplinares. (FREITAS; PEREIRA, 2013, p. 149)

A noção de ecossistema comunicativo é cara para a Educomunicação como campo de conhecimento que se constitui na interface Educação/Comunicação preocupado em construir ecossistemas comunicativos:

Definimos, assim, a Educomunicação como o conjunto das ações inerentes ao planejamento, implementação e avaliação de processos, programa e produtos destinados a criar e a fortalecer ecossistemas comunicativos em espaços educativos presenciais ou virtuais, assim como a melhorar o coeficiente comunicativo das ações educativas, incluindo as relacionadas ao uso dos recursos da informação no processo de aprendizagem. (SOARES, 2002, p. 24)

A Educomunicação preocupa-se em criar e fortalecer espaços de ações inclusivas, democráticas, participativas, criativas e críticas que levem em consideração o ambiente midiático (SOARES, 2011). Para isso, pauta-se na concepção educacional de Paulo Freire e busca o diálogo estratégico para o convívio humano, resolução de conflitos, consecução de objetivos comuns, realização de projetos coletivos. "Viver em um ecossistema comunicativo, onde o intercâmbio entre diferentes telas e plataformas requer exploração criativa e descobertas, faz com que estejamos sempre com possibilidades de educar-nos, de aprender" (OROZCO-GÓMEZ, 2014, p. 270). Os diversos modos de interação, Estrela, Círculo e Rede, implicam cada um em um ecossistema comunicativo próprio, menos ou mais participativo, menos ou mais interativo. Pelo seu caráter dinâmico, colaborativo e descentralizado, com possibilidades diversas de dinâmicas comunicacionais, um ecossistema educomunicativo encontra mais condições de realizar uma prática pedagógica educomunicativa se adotar o Modo Rede de comunicação. 


\section{O que desejamos: um ecossistema educomunicativo}

Em uma entrevista para a Revista Dialogia, ao ser perguntado sobre que mudanças visualiza como necessárias para a educação brasileira, levando em consideração conceitos como "ecossistemas de aprendizagem”, “ecologia da aprendizagem”, entre outros, José António Moreira, pesquisador e educador português, ressalta a necessidade de mudanças no paradigma educacional considerando as novas formas de pensar e viver em tempos de cultura digital.

Com efeito, os ecossistemas digitais de aprendizagem, tal como os conhecemos, estão sendo constantemente desafiados pelo enorme fluxo de conteúdos, pelas múltiplas plataformas e sistemas de medias, que circulam pela nossa cultura, e que provocam um conjunto de mudanças, não só tecnológicas, mas também sociais e culturais. [...] há a necessidade, efetiva, de criar redes dinâmicas e ecológicas capazes de responder aos desafios da sociedade. (MOREIRA, 2020, p. 4)

Teresa Romeu Fontanillas et al. (2020) afirmam que desde os anos 1990 o enfoque ecológico para a educação digital tem possibilitado a proliferação de termos como desenvolvimento de habilidades, aprendizagem colaborativa, desenho de aprendizagem com tecnologias, entre outros, que incorporaram a noção de aprendizagem de diferentes tipos. O conceito de ecossistema de aprendizagem tem sido utilizado com mais intensidade em organizações e empresas (GARCÍA-HOLGADO; GARCÍA-PEÑALVO, 2016). Com o desenvolvimento das tecnologias digitais e o atravessamento da sociedade pela cultura digital, pelas possibilidades de comunicação e conectividade que trazem, faz sentido pensar nas contribuições ou nas relações intrínsecas que trazem para a educação. "Preocupar-se com ecossistemas comunicativos em espaços educacionais é levar em conta que a escola é espaço complexo de comunicações, no qual o educador deve considerar o entorno cultural do aluno e seus pares de diálogo [...]” (SARTORI, 2010, p. 46).

Ismar Soares (2002) chamou a atenção para a existência de ecossistemas comunicativos no plural porque existem processos de trocas simbólicas mais ou menos interativos. "Um dos deslocamentos a serem contemplados, numa visão mais dialética da presença tecnológica no mundo, diz respeito à transferência de um modelo de 
comunicação linear a um modelo em redes, de comunicação distribuída." (SOARES, 2002, p. 20). Como as relações humanas não são sempre dialógicas e por vezes mantêm uma relação conflitiva com o ambiente, a ideia de fortalecimento do diálogo busca a transição de modelos lineares de comunicação para modelos de comunicação em rede, de modelos autoritários para modelos dialógicos. Ecossistemas comunicativos e ecossistemas de aprendizagem partilham do mesmo projeto: proporcionar educação no contexto da cultua digital. Quando a concepção de aprendizagem e a de comunicação se dão pela ideia da dialogicidade e da ação em rede, temos um ecossistema educomunicativo.

Na Figura 1, temos um esquema de ecossistema educomunicativo a partir da noção básica de ecossistemas. Com o proposto esquema, buscamos contemplar a noção de ecossistema pontuando as relações bióticas e abióticas, funções, elementos e objetivos que todo ecossistema deve apresentar.

Fig. 1 - Esquema de um ecossistema educomunicativo

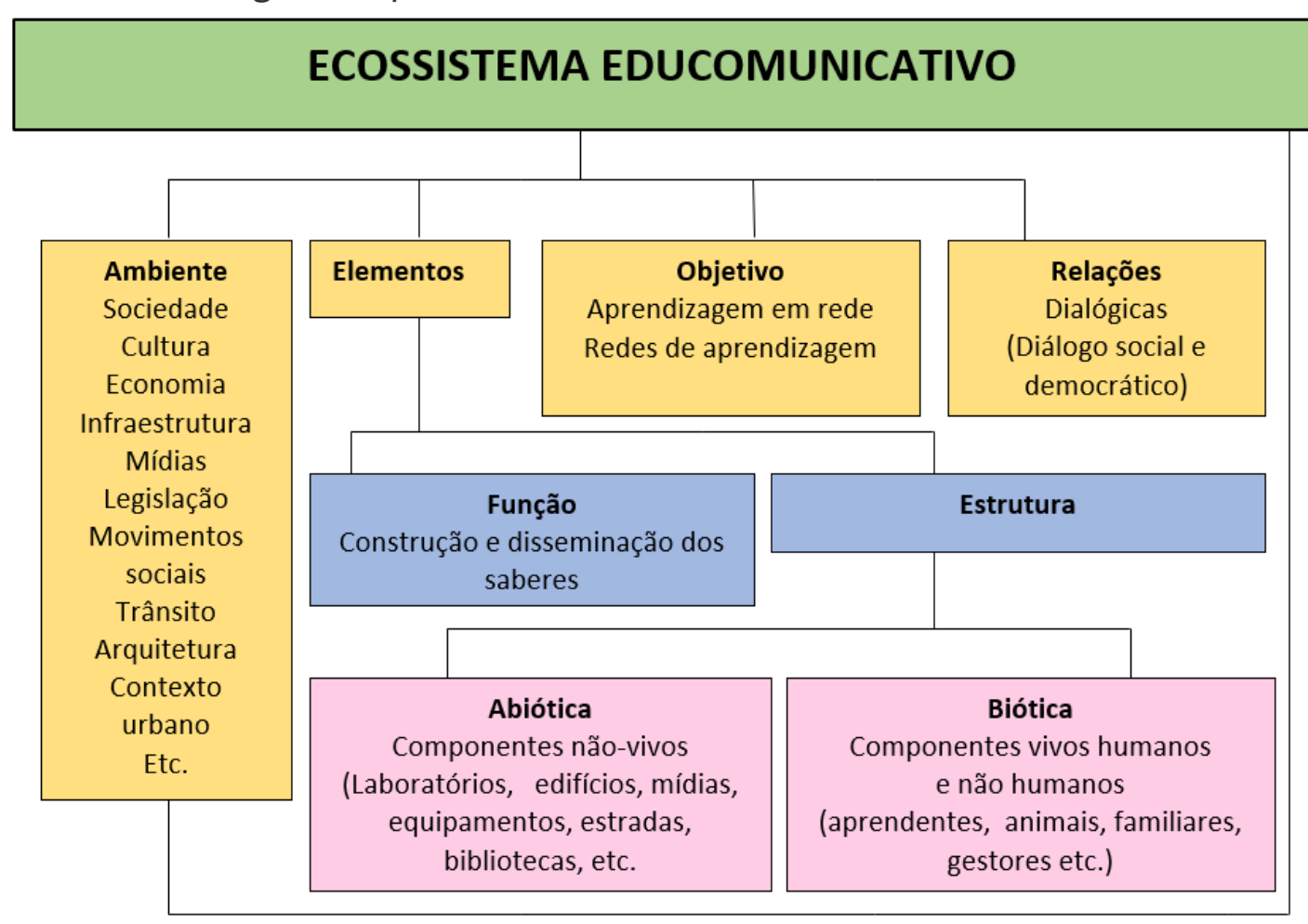

Fonte: Elaborado pela autora (2021). 
Embora o esquema acima seja um recurso visual estático, as fronteiras entre as

Embora o esquema acilna seja um recurso visual estático, as fronteiras entre as funções abióticas e o ambiente se entrelaçam; objetivo e função podem ser percebidos como método de ação; a função biótica é diversa e de difícil delimitação em redes abertas e flexíveis, enfim, os quadros são meramente organizativos. Não constam no esquema apresentado o fluxo energético e a ciclagem de materiais que podem se entendidos como um complexo de relações entre todos esses elementos e que podem indicar os processos de construção dos sentidos e seus fluxos nas relações de interdependências intrínsecas aos componentes do ecossistema educomunicativo. Como o ambiente é aberto, um ecossistema educomunicativo não é um sistema fechado e existe mútua influência, a alteração em um acarreta alterações no outro. A ligação com o meio ambiente é permanente, o que implica que todos os componentes sofrem a ação do meio e agem sobre o mesmo. Essa interdependência é representada no esquema pela linha longa que une o ambiente ao ecossistema educomunicativo.

Entre as vantagens que podem ser percebidas pela representação esquemática de um ecossistema educomunicativo está a discussão sistemática e relacional dos papéis que jogam mídias, infraestrutura tecnológica, cultura, contexto econômico, conjunto de profissionais envolvidos em um determinado ecossistema educomunicativo. Podemos compreender de que modo problemas de infraestrutura, como falta de acesso à internet, podem impactar as relações dialógicas entre professores e estudantes em um ecossistema educomunicativo escolar; como relações dialógicas fracas contribuem para dificuldades de mobilizar mídias para execução de práticas pedagógicas educomunicativas; como o ambiente reage de modo a contribuir para o bom funcionamento do ecossistema; como se relacionam conteúdos escolares e saberes e que sujeitos podem contribuir em uma rede de aprendizagem, por exemplo.

Esse pode ser um programa de pesquisa a respeito das implicações que a pandemia causada pelo SARS-CoV-2 trouxe para a educação escolar uma vez que, em geral, famílias eram consideradas elementos do ambiente, portanto externos ao ecossistema educomunicativo escolar. Com a Pandemia de Covid-19, a escola entrou nas casas e essa fronteira se desfez, transformando pais em elementos bióticos cotidianos e estratégicos. Que impactos essa "quebra" trouxe para as relações entre pais e escola? A convivência quase compulsória com as mídias chegou a transformar as relações limitadas 
ao uso instrumental das mesmas, configurando redes de aprendizagens mais abrangentes? A cultura midiática das crianças adquiriu sentido no processo de aprendizagem no contexto do ensino remoto?

Os estudos desses desequilíbrios e tensões precisam levar em conta se houve condições para o desenvolvimento de práticas pedagógicas que elevassem os ecossistemas comunicativos intrínsecos das escolas ao patamar de um ecossistema educomunicativo. Dessa análise, poderemos identificar pontos de referência para pensar e propor avanços para uma prática pedagógica educomunicativa no pós-pandemia.

\section{Referências}

CAMERON, Laura. Sir Arthur Tansley. Oxford Bibliographies. Oxford University Press, New York, p. 3-10, 2017. Disponível em:

https://www.oxfordbibliographies.com/view/document/obo-9780199830060/obo9780199830060-0094.xml. Acesso em: 09 de fev. 2021.

ECO, Umberto. Apocalípticos e integrados. 6. ed. São Paulo: Editora Perspectiva, 2004.

EGERTON, Frank. History of ecological sciences, part 47: Ernst Haeckel's ecology. Bulletin. Ecological Society of America. Washington, n. 3 v. 94, p. 216-221, 2013. Disponível em: https://esajournals.onlinelibrary.wiley.com/toc/23276096/2013/94/3. Acesso em: 9 de fev. 2021. 
FONTANILLAS, Teresa Romeu et al. Ecologías de aprendizaje para usar las TIC inspirándose en docentes referentes. Comunicar, Huelva, n. 62, v. 28, p. 31-42, 2020.

FREIRE, Paulo. Extensão ou Comunicação? 4. ed. Rio de Janeiro: Paz e Terra, 1979.

FREITAS, Susy Elaine da Costa; PEREIRA, Mirna Feitoza. Paradigmas científicos para o estudo dos ecossistemas comunicacionais In: SEIXAS, Netília Silva dos Anjos et al. Comunicação: visualidades e diversidades na Amazônia. Belém: FADESP, 2013. p.149-172. Disponível em: https://livroaberto.ufpa.br/jspui/bitstream/prefix/171/1/ Livro_ComunicacaoVisualidadesDiversidades.pdf. Acesso em: 20 dez. 2020.

GARCÍA-HOLGADO, Alícia; GARCÍA-PEÑALVO, Francisco José. Architectural pattern to improve the definition and implementation of eLearning ecosystem. Revista Science of Computer Programming, Amsterdam, n.129, p. 20-34, 2016. Disponível em: https://www.sciencedirect.com/science/article/pii/S0167642316300259. Acesso em: 14 dez. 2020.

HANNAN, Michael. T; FREEMAN, John. Population ecology of organization. American Journal of Sociology, Chicago, v. 82, n. 5, 1977. Disponível em: https://www.journals.uchicago.edu/doi/abs/10.1086/226424. Acesso em: 20 dez. 2020.

ISIE. History of the ISIE. [Connecticut]: International Society of industrial Ecology, 2009. Disponível em: https://web.archive.org/web/20090408080134/http:/www.is4ie.org/ history. Acesso em: 20 dez. 2020.

JENKINS, Henry. Cultura da convergência. 2. ed. São Paulo: Aleph, 2009.

LÉVY, Pierre. As tecnologias da inteligência: o futuro do pensamento na era da informática. Rio de Janeiro: Editora 34, 1993.

LÉVY, Pierre. A máquina universo: criação, cognição e cultura informacional. Porto Alegre: Artmed, 1998.

LÉVY, Pierre. A inteligência coletiva: por uma antropologia do ciberespaço. São Paulo: Edições Loyola, 1998.

LIMA JÚNIOR, Walter Teixeira. Modelo de negócio da TV digital no Brasil pode abrir espaço para IPTV. In: SQUIRRA, Sebastião; FECHINE, Yvana. Televisão digital: desafios para comunicação. Porto Alegre: Sulinas, 2009. p. 366-380.

MARTÍN-BARBERO, Jesús. Desafios culturais: da comunicação à educomunicação. In: CITELLI, Adilson; COSTA, Marília Cristina (orgs.). Educomunicação: construindo uma nova área de conhecimento. São Paulo: Paulinas, 2011. p.121-134.

MARTÍN-BARBERO, Jesús. La educación en el ecosistema educativo. Comunicar, Huelva, n. 13, p.13-21, 1999. Disponível em:

https://dialnet.unirioja.es/descarga/articulo/229963.pdf. Acesso em: 20 dez. 2020. 
MARTÍN-BARBERO, Jesús. Globalização comunicacional e transformação cultural. In: MORAES, Dênis (org.). Por uma outra comunicação: mídia, mundialização cultural e poder. Rio de Janeiro: Record, 2003. p.57-86.

MARTINS, Hermínio. Tecnologia, modernidade e política. Revista Lua Nova, São Paulo, n. 40/41, p. 289-323, 1997. Disponível em: https://www.scielo.br/pdf/In/n40-41/a13n4041.pdf. Acesso em: 09 fev. 2021.

NEVES, Carmen Moreira de Castro. A educação a distância na América Latina: o caso do Brasil. In: MENA, Marta. La educación a distancia em América Latina. Modelos, tecnologias e realidades. Buenos Aires: La Crujia: Stella: ICDE: UNESCO, 2004. p.57-68.

OROZCO GÓMEZ, Guillermo. Entre telas: novos papéis comunicativos e educativos dos cidadãos. In: APARICCI, Roberto. (org.). Educomunicação: para além do 2.0. São Paulo: Paulinas, 2014. p.267- 279.

PARRA, Nélio. Metodologia dos recursos audiovisuais. 1. ed. São Paulo: Saraiva, 1977.

RÜDIGER, Francisco. As teorias da cibercultura. Perspectivas, questões e autores. 2. ed. Porto Alegre: Sulinas, 2013.

SARTORI, Ademilde Silveira. Communication in the distance education. Interaction mode and pedagogical design. In: CALAFATE, Carlos; LAZINICA, Aleksander (orgs.). Technology, education and development. Croácia: Intech, 2009. p.75-91. Disponível em:

https://www.intechopen.com/books/technology-education-and-

development/communication-in-the-distance-education-interaction-modes-and-thepedagogical-design. Acesso em: 20 dez. 2020.

SARTORI, Ademilde Silveira. A Educomunicação e sua relação com a escola: a promoção de ecossistemas comunicativos e a aprendizagem distraída. Revista Comunicação, mídia e consumo, São Paulo, v. 7, n. 19, p. 33-48, 2010. Disponível em:

http://revistacmc.espm.br/index.php/revistacmc/article/view/193. Acesso em: 20 dez. 2020.

SARTORI, Ademilde Silveira. Comunicação, educação e direitos humanos. Um deslocamento de referências. In: RADATZ, Vera Lucia Spacil (org.). Educação e comunicação para os direitos humanos. ljuí: Ed. Unijuí, 2015. p. 103122.

SARTORI, Ademilde Silveira. A educomunicação na EaD: inter-relações entre a educação e a comunicação. In: FIUZA, Patricia Jantsch; LEMOS, Robson Rodrigues. Inovação em educação: perspectivas do uso das tecnologias interativas. Jundiaí: Paco Editorial, 2017. p.15-36.

SOARES, Ismar de Oliveira. Gestão comunicativa: caminhos da educomunicação. Revista Comunicação \& Educação, São Paulo, n. 23, p. 16-25, 2002. 
SOARES, Ismar de Oliveira. Educomunicação: o conceito, o profissional e a aplicação. São

Paulo: Paulinas, 2011. (Coleção Educomunicação).

MOREIRA, José António Marques. Pedagogias em diferentes espaços educativos.

Entrevista cedida a Adriana Aparecida de Lima Terçariol e Rosiley Aparecida Teixeira.

Dialogia, São Paulo, n. 34, p. 2-7, jan./abr. 2020. Disponível em:

https://doi.org/10.5585/Dialogia.N34.17342. Acesso em: 14 dez. 2020.

UNESCO. La educación en América Latina y el caribe ante el COVID-19. Disponível em: https://es.unesco.org/fieldoffice/santiago/covid-19-education-alc/respuestas. Acesso em: 14 dez. 2020.

VASSALO DE LOPES, Maria Immacolata. Pesquisas de recepção e educação para os meios. In: CITELLI, Adilson; COSTA, Maria Castilho (orgs.). Educomunicação: construindo uma nova área de conhecimento. São Paulo: Paulinas, 2011. p. 43-51. 